\title{
Study on the Activity of Calcium Silicate Slag
}

\author{
ZHAN Jiayu, ${ }^{1, a}$, GENG Chunlei ${ }^{1, b}$, YANG Feihua ${ }^{1, c}$, LI Wanmin $^{1, d}$, , YANG \\ Chuang ${ }^{1, \mathrm{e}}$, YANG Zhijie ${ }^{2, \mathrm{f}}$ \\ ${ }^{1}$ State Key Laboratory of Solid Waste Reuse for Building Materials, Beijing Building Materials \\ Academy of Science Research, Beijing100041, P.R.China \\ ${ }^{2}$ National Energy Key Lab of High Alumina Coal Development and Utilization, Datang International \\ High Alumina Coal R\&D Center, Inner Mongolia 010321, P.R.China \\ azhanjiayu1981@126.com, ${ }^{\mathrm{b}} 18611669792 @ 163 . c o m,{ }^{c}$ chyangfeihua@126.com,

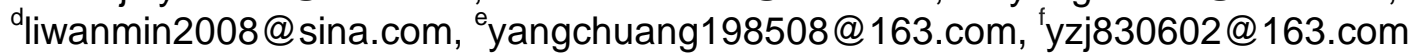

\begin{abstract}
Keywords: Calcium silicate slag, Activity index, Storage time, Particle size distribution
Abstract. Calcium silicate slag is a waste discharged during alumina extraction process from fly ash was investigated. In this study, its chemical composition, mineral composition and morphology of calcium silicate slag were obtained, and the variation of particle size distribution with different storage time was evaluated. The particle size increased along with the storage time within 90 days, confirming the hydration reaction in this period. The activity index results indicated that the formation of large particle had no effect on the hydration activity.
\end{abstract}

\section{Introduction}

Calcium silicate slag is a solid waste generated during alumina extraction from high-alumina fly ash via alkaline process[1]. Calcium silicate slag consists mainly of $\mathrm{CaO}$ and $\mathrm{SiO}_{2}$, with the major crystalline phases of $\mathrm{C}_{2} \mathrm{~S}$ and $\mathrm{C}_{3} \mathrm{~A}$. About 2.2 2.5 tons of calcium silicate slag will be discharged when producing 1 ton of $\mathrm{Al}_{2} \mathrm{O}_{3}$. The disposal of such a large quantity of waste requires a lot of land and has caused many serious environmental problems.

Jinshan Zhang et al.[2] used calcium silicate in combination with gypsum, fly ash, cement and reinforcing fiber to prepare calcium silicate board with flexural strength of up to 9.2 MPa. Jiang Liu et al.[3] investigated the use of calcium silicate slag as cement admixture. The compressive strength of non-dealkalizated calcium silicate slag cement is higher than dealkalizated calcium silicate slag cement during the early hydration. The cement compressive strength using dealkalizated calcium is apparently higher than using non-dealkalizated calcium silicate slag at 90 days. Ping Wen [4] used calcium silicate slag as a high-volume component of raw meal to replace limestone to produce Portland cement clinker. Jinshan Zhang et al [5] found that calcium silicate slag could be used to produce aerated concrete. With the content of calcium silicate slag up to $50 \%$, the strength and density can meet the request of Chinese standard. Na Zhang [6] produced cementitious material from calcium silicate slag, which exhibited excellent physical and mechanical properties. The leaching toxicity and radioactivity test results indicated that the cementitious material is environmentally acceptable.

In this study, we focus on the activity of calcium silicate slag. The chemical and mineral composition of calcium silicate slag was extensively study. The relationship between particle size distribution and storage time, and the influence of particle size distribution on the activity index was evaluated.

\section{Experimental Section}

Materials. Calcium silicate slag was supplied by Datang international high alumina Coal R\&D center. Methods. Calcium silicate was dried at $105^{\circ} \mathrm{C}$ in an oven until constant mass. The particle size distribution, XRD analysis, SEM observation, chemical composition and activity index of the dried calcium silicate slag were performed.

Characterization. The chemical composition was analyzed using X-ray fluorescence spectrometer. RIGAKU Ultima IV XRD equipped with $\mathrm{Cu}$ target was used for analyzing minerals, and mineral 
components of calcium silicate slag were quantitatively determined. Morphology of calcium silicate slag was recorded on a Hitachi S-3400 scanning electron microscope (SEM) operating at an accelerating voltage of $5 \mathrm{kV}$.

Particle size distribution was conducted by sieves with $0.1 \mathrm{~mm}, 0.3 \mathrm{~mm}, 1.18 \mathrm{~mm}$ and $2 \mathrm{~mm}$ aperture, respectively. The wet calcium silicate slag was dried and particle size distribution was tested at 15-day intervals. Activity index was performed according to Chinese standard GB/T 1596-2005. Calcium silicate slag with different particle size ( $>2 \mathrm{~mm}, 1.18 \sim 2 \mathrm{~mm}, 0.3 \sim 1.18 \mathrm{~mm}, 0.1 \sim 0.3 \mathrm{~mm}$ and $<0.1 \mathrm{~mm}$ ) was respectively grinded in ball mill for $20 \mathrm{~min}$ prior to use. Mortar specimens with dimensions of 40 $\mathrm{mm} \times 40 \mathrm{~mm} \times 160 \mathrm{~mm}$ were made with a water/cement ratio of 0.5 and cement/sand ratio of 1: 3 . For the test sample, $30 \mathrm{wt} \%$ content of cement was substituted by calcium silicate slag. For the contrast sample, calcium silicate slag wasn't used. The $28 \mathrm{~d}$ compressive strength ratio between the test sample and contrast sample was identified as the activity index of calcium silicate slag.

\section{Results and Discussion}

As shown in Table 1, the main chemical composition of calcium silicate slag is $\mathrm{CaO}, \mathrm{SiO}_{2}$ and $\mathrm{Al}_{2} \mathrm{O}_{3}$. It has to be noticed that the calcium silicate slag contains small amount of alkali $\left(\mathrm{Na}_{2} \mathrm{O}\right.$ and $\left.\mathrm{K}_{2} \mathrm{O}\right)$. Therefore, the environmental problems caused by alkali residue should be seriously considered.

Table1. Chemical and mineral composition of calcium silicate slag

\begin{tabular}{ccccccccccc}
\hline \multicolumn{10}{c}{ Chemical composition(\%) } \\
\hline $\mathrm{CaO}$ & $\mathrm{MgO}$ & $\mathrm{Al}_{2} \mathrm{O}_{3}$ & $\mathrm{SiO}_{2}$ & $\mathrm{P}_{2} \mathrm{O}_{5}$ & $\mathrm{SO}_{3}$ & $\mathrm{~K}_{2} \mathrm{O}$ & $\mathrm{Na}_{2} \mathrm{O}$ & $\mathrm{Fe}_{2} \mathrm{O}_{3}$ & $\mathrm{TiO}_{2}$ & LOI \\
46.61 & 3.35 & 5.98 & 27.12 & 0.10 & 0.59 & 0.36 & 3.68 & 2.03 & 1.14 & 8.70 \\
\hline \multicolumn{10}{c}{ Mineral composition(\%) } \\
\hline $\mathrm{C}_{2} \mathrm{~S}$ & $\mathrm{C}_{3} \mathrm{~A}$ & $\mathrm{C}_{3} \mathrm{~S}$ & $\mathrm{C}_{4} \mathrm{AF}$ & $\mathrm{CaCO}_{3}$ & $\alpha-\mathrm{CaO} \cdot \mathrm{SiO}_{2}$ & $\mathrm{CaO} \times \mathrm{SiO}_{2}$ & $\mathrm{MgO}$ & Amorphous phase \\
36.17 & 15.03 & 5.50 & 2.68 & 5.64 & 1.48 & 1.20 & 2.82 & 29.50 \\
\hline
\end{tabular}

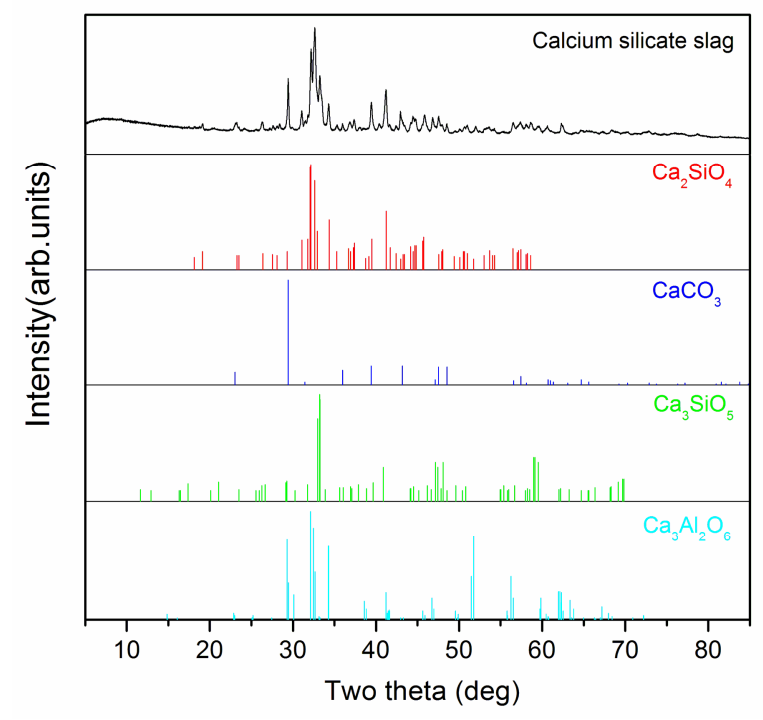

Fig.1. XRD spectrum of calcium silicate slag

The XRD spectrum of calcium silicate slag is shown in Fig. 1, and the amounts of minerals from QXRD are presented in Table 1. As shown in Fig. 2, the major mineral components of calcium silicate slag are $\mathrm{C}_{2} \mathrm{~S}, \mathrm{C}_{3} \mathrm{~A}, \mathrm{C}_{3} \mathrm{~S}, \mathrm{CaCO}_{3}$ and amorphous phase. The hydration reaction can occur due to the presence of $\mathrm{C}_{2} \mathrm{~S}, \mathrm{C}_{3} \mathrm{~A}$ and $\mathrm{C}_{3} \mathrm{~S}$. Specifically, the amorphous phase indicates the formation of calcium silicate hydrate(C-S-H) gel and C-S-A-H gel. This is because the aluminate has to be extracted from the clinker by water. Partial hydration reaction may occur during the extraction process. 


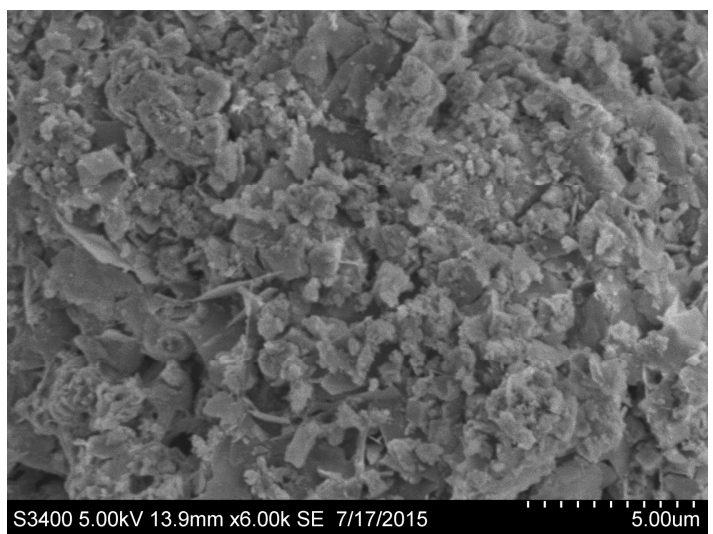

Fig.2. SEM image of calcium silicate slag

The morphology of calcium silicate slag has been observed by SEM as shown in Fig.2. The calcium silicate slag particles are irregular. The hydration products formed during the aluminate extraction process may coat on the surfaces of calcium silicate slage particles, inhibiting the continued hydration reaction. Therefore, it is important to know the activity of calcium silicate slag for its application.

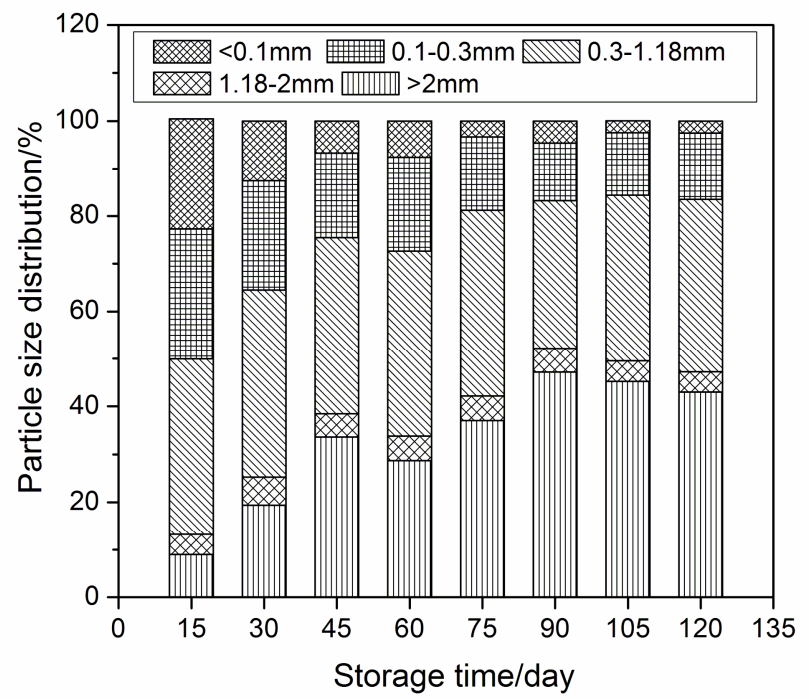

Fig.3. The correlations between the storage time and particle size distribution of calcium silicate slag.

The newly generated calcium silicate slag contains large proportion of water, and the hydration reaction will gradually occur under this condition. The variation of particle size distribution with storage time was investigated as shown in Fig.3. It can be seen that the amount of calcium silicate slag with particle size less than $0.3 \mathrm{~mm}$ decreased with storage time. The amount of calcium silicate slag with larger particle size $(>2 \mathrm{~mm})$ apparently increased with storage time. After 90 days, the particle size distribution is almost changed. This result indicates that the hydration reaction occurs within 90days.

The activity index of calcium silicate slag with different size was measured respectively. It can be seen from Fig. 4 that the activity index is about $60 \%$, and there is no change in different particle size. This result indicates that the formation of large particle has no effect on the hydration activity. 


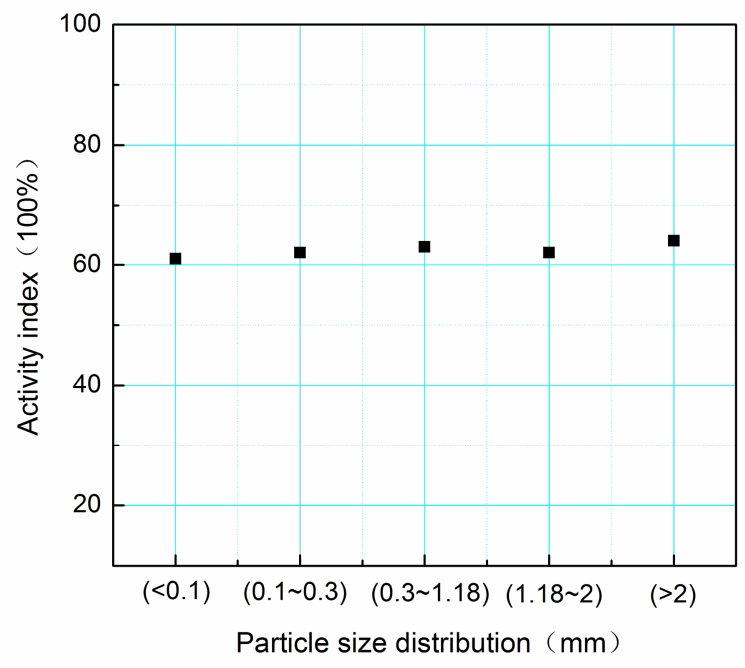

Fig.4. The correlations between activity index and particle size distribution of calcium silicate slag.

\section{Conclusions}

We have investigated the activity of calcium silicate slag which was generated from the alumina extraction from fly ash. Calcium silicate slag consists mainly of $\mathrm{CaO}, \mathrm{SiO}_{2}$ and $\mathrm{Al}_{2} \mathrm{O}_{3}$, with main mineral phases of $\mathrm{C}_{2} \mathrm{~S}, \mathrm{C}_{3} \mathrm{~A}, \mathrm{C}_{3} \mathrm{~S}$ and $\mathrm{CaCO}_{3}$. The particle size of calcium silicate slag apparently increased within 90 days along with the increase of storage time, suggesting the hydration reaction occurred in this period. The activity index of calcium silicate slag is about $60 \%$. There was no obvious change in activity index at different particle size distribution.

\section{Acknowledgements}

This work was financially supported by the Beijing Municipal Science and Technology Project (No.Z151100004915009).

\section{References}

[1] S.J.Song, D.S.Kong, L.H.Wang and X.W.Bai: Yunnan Chemical Technology Vol.40 (2013), p.52 (in Chinese)

[2] J.S. Zhang, J.P.Ye, J.M.Sun, Y.D.Cao and Z.Z.Geng: New Building Materials Vol.1 (2014), p.54 (in Chinese)

[3] J. Liu, J.B.Zhang, J.M. Sun, H.X.Wang, J.Y.Ye and D.Shi: New Building Materials Vol.12 (2012), p.37 (in Chinese)

[4] P.Wen: Research\&Application Vol.5 (2012), p. 54 (in Chinese)

[5] J.S.Zhang, J.M.Zhao, J.P.Ye, Z.Z.Geng and Y.T.Zheng : Fly Ash Comprehensive Utilization Vol.1 (2013), p. 40 (in Chinese)

[6] N.Zhang, H.Li, Y.Zhao and X.Liu: J.Hazard.Mater Vol.306 (2016), p.67 